\title{
Pressure resistance of thin ionic liquid membranes using tailored ceramic supports
}

\author{
R. Kreiter \\ J.P. Overbeek \\ L.A. Correia \\ J.F. Vente \\ Published in Journal of Membrane Science, Volume 370, issues 1-2, 15 March 2011,
} pages $175-178$ 


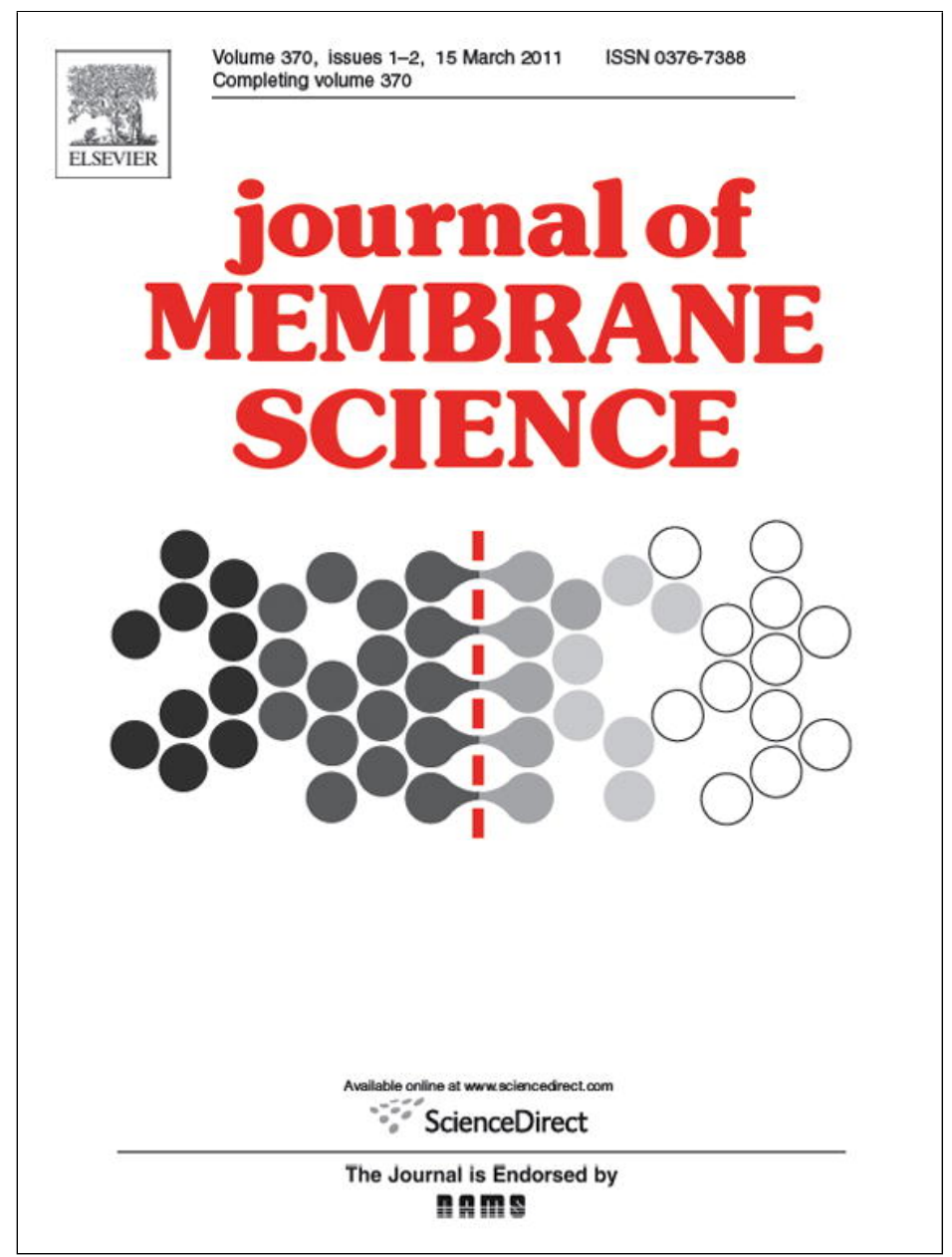

This article appeared in a journal published by Elsevier. The attached copy is furnished to the author for internal non-commercial research and education use, including for instruction at the authors institution and sharing with colleagues.

Other uses, including reproduction and distribution, or selling or licensing copies, or posting to personal, institutional or third party websites are prohibited.

In most cases authors are permitted to post their version of the article (e.g. in Word or Tex form) to their personal website or institutional repository. Authors requiring further information regarding Elsevier's archiving and manuscript policies are encouraged to visit:

http://www.elsevier.com/copyright 
Letter to the Editor

Pressure resistance of thin ionic liquid membranes using tailored ceramic supports

\section{A R T I C L E I N F O}

\section{Keywords:}

Supported liquid membrane

Pressure resistance

Ionic liquid

Membrane

Ceramic

Mesoporous

\begin{abstract}
A B S T R A C T
For the first time, a thin ionic liquid membrane that is resistant up to 55 bar trans-membrane pressure is presented. The ionic liquid is confined in a tubular ceramic-supported mesoporous containment layer of $1.5 \mu \mathrm{m}$. Gas permeances and permselectivity values for $\mathrm{CO}_{2}, \mathrm{CH}_{4}$, ethylene, and ethane are discussed and related to the properties of the ionic liquids.
\end{abstract}

(c) 2010 Elsevier B.V. All rights reserved.
Ionic liquids (ILs) and other designer solvents are widely investigated because of their low vapour pressures, thermal stability, and excellent solvent properties [1]. In addition, specific ionic liquids have affinities that allow molecular separations in membrane systems [2] or absorber columns. For instance, imidazolium-based ILs have been proposed for $\mathrm{CO}_{2}$ capture $[3,4]$ and olefin/paraffin separations [5]. Recently, a combined theoretical and experimental overview of $\mathrm{CO}_{2}$ solubility in a range of ionic liquids was reported [6]. These promising adsorption data have been reported for bulk IL samples in non-continuous processes. Continuous separation processes such as membrane separations are potentially more energy efficient. Supported IL membranes (SILMs) are developed to allow for membrane operation of the IL separating solvent [2]. Polymeric substrates were proposed as support for such ionic liquid membranes [7-10]. However, the durability of polymer-based SILMs is expected to be limited, especially at industrially relevant conditions. Total pressures in $C_{2}$ and $C_{3}$-splitters are typically 20 bar [11] and in natural gas treatment they are over 50 bar [12]. Ceramic membrane supports, with a higher pressure drop resistance, have also been proposed for the preparation of SILMs [13,14]. Measurements are currently limited to trans-membrane pressures of 7 bar [15]. In addition, common preparation routes for ceramicsupported liquid membranes in general result in flooded supports and high membrane layer thicknesses. The kinetics of IL imbibition in ceramic supports were reported recently [13]. Without appropriate precautions, IL layers of over $100 \mu \mathrm{m}$ thick are formed rapidly in asymmetric ceramic supports. Here, we present mesoporous ceramic support layers as pressure resistant support system for ionic liquid membranes. The target was to develop a pressure resistant support and impregnation procedure that results in thin liquid membranes that could be applied up to pressures over 50 bar.

Careful tailoring of the pore size of the containment layer is required, to retain a liquid in an inorganic porous membrane. The trans-membrane pressure needs to be balanced by the capillary forces of the liquid in the pores. The maximum pore diameters that can be used at a given surface tension can be estimated using the Young-Laplace Eq. (1), in which $P$ is the capillary pressure, $\gamma$ is the surface tension of the liquid, $\theta$ is the contact angle, and $d$ is the pore diameter. Complete wetting of the support material by the ionic liquid is assumed $(\theta=0)$.

$\Delta P=\frac{4 \gamma \cos \theta}{d}$

As lower limit of IL surface tension $(\gamma)$ was taken $30 \mathrm{mN} / \mathrm{m}$, which is a realistic lower value for common imidazolium-based ILs. With a pressure drop criterion of at least 40 bar, a maximum allowable pore diameter of $30 \mathrm{~nm}$ was calculated. We selected $\gamma$-alumina as an appropriate material for the containment layer. The Boehmite sol synthesis procedure in the $\gamma$-alumina preparation [16] was chosen such that average pore diameters of $4 \mathrm{~nm}$ were obtained. These mesoporous membrane layers have a high-end tail of the pore distribution up to about $20 \mathrm{~nm}$ [17]. This value is well below the $30 \mathrm{~nm}$ target, while the mean pore size of $4 \mathrm{~nm}$ still allows for large gas flows.

To combine a low support flow resistance with a sufficient strength, the mesoporous containment layer needs to be supported by a macroporous support system. Because of the targeted pressure drop of at least 40 bar, a tubular support was selected. In-house developed tubular multilayered ceramic membrane tubes with an outer diameter of $1.4 \mathrm{~cm}$ and $30 \mathrm{~cm}$ length were used. Detailed specifications and preparation procedures are described elsewhere [17]. One of the key quality indicators of the mesoporous containment layer is the defect density. This value strongly depends on the quality of the macroporous support layers. A successful strategy to maximize the macroporous support quality is presented elsewhere [18].

Based on absorption data from literature $[3,19]$ the ionic liquids 1-butyl-3-methylimidazolium trifluoroacetate ([BMIm]TFA) and [BMIm]TFA.AgTFA, containing silver trifluoroacetate $\left(x_{\mathrm{Ag}}=0.2\right)$, were selected for the separation of ethylene/ethane. 1-(3-aminopropyl)-3-methylimidazolium bis(trifluoromethylsulfonyl)imide 

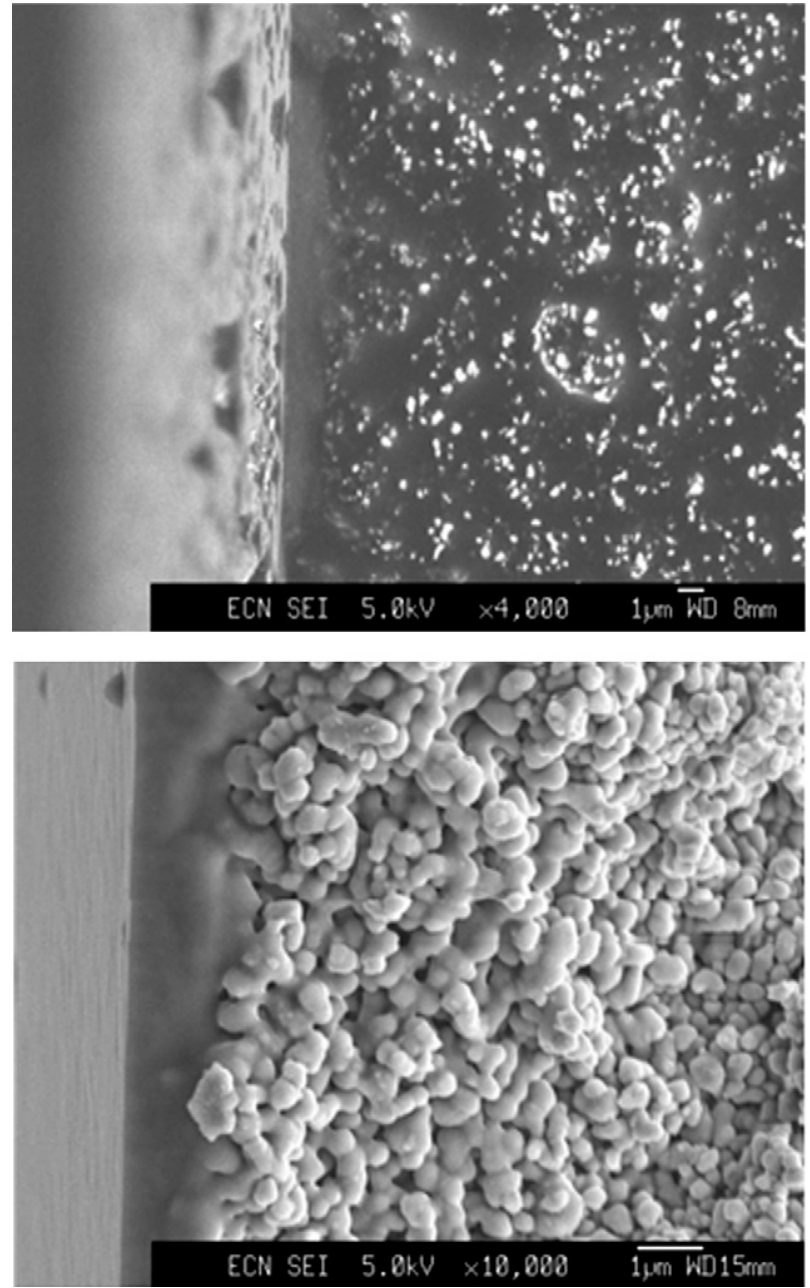

Fig. 1. Results of impregnation via conventional coating (top, $4000 \times$ ) and restricted flow impregnation procedure (bottom, $10.000 \times$ ).

([APMIm]NTf $f_{2}$ ) was selected for $\mathrm{CO}_{2}$ and $\mathrm{CH}_{4}$ permeation experiments.

In agreement with an earlier report on ceramic supports for IL membranes, [13] conventional coating procedures resulted in impregnation of both the mesoporous and the macroporous support layers. Effective membrane thicknesses up to hundreds of microns (Fig. 1, top) were obtained, severely limiting gas permeance. Therefore, selective impregnation of only the outer mesoporous containment layer was targeted, without flooding the macroporous support layer. This controlled impregnation was achieved by a restricted flow coating procedure, in which the amount of IL fed to the support could be limited adequately. As a result, the effective membrane thickness was limited to the thickness of the mesoporous layer of about $1.5 \mu \mathrm{m}$ (Fig. 1, bottom).

Pressure resistance tests up to a pressure difference of $55 \mathrm{bar}$ were performed on several supported ionic liquid membranes thus prepared, using $\mathrm{N}_{2}$ as permeating gas. A sudden increase by several orders of magnitude would be indicative of blowout effects. However, such increases were not observed. As a representative example the results for the silver containing IL [BMIm]TFA.AgTFA are shown (Fig. 2). The $\mathrm{N}_{2}$ permeance increases with increasing pressure from $5 \times 10^{-9} \mathrm{~mol} / \mathrm{m}^{2} \mathrm{~Pa}$ at 10 bar to $14 \times 10^{-9} \mathrm{~mol} / \mathrm{m}^{2} \mathrm{Pas}$ at $55 \mathrm{bar}$. These values are three orders of magnitude lower than that of the empty support. Further proof of

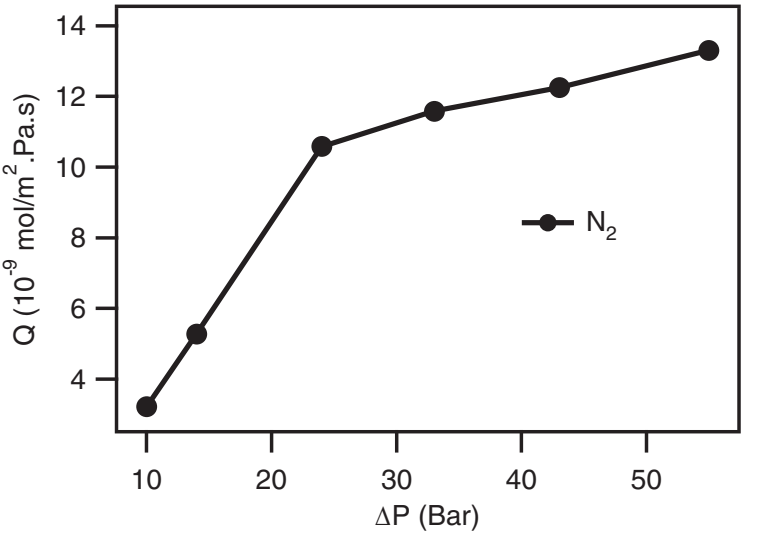

Fig. 2. Pressure test of supported [BMIm]TFA.AgTFA membrane; $N_{2}$ permeance $(Q)$ shown versus the transmembrane pressure $(\Delta P)$.

the pressure drop resistance can be found in the fact that the permeance was constant in time, after a short stabilization period. The observed slight pressure dependence of the permeance is consistent with the combination of viscous flow through the few defect pores and transport through the IL.

Single gas permeance experiments with a dead end experimental set up were performed to assess the applicability of these ceramic-supported IL membranes in gas separation of $\mathrm{CO}_{2} / \mathrm{CH}_{4}$ or olefin/paraffin mixtures. The permeance of $\mathrm{CH}_{4}$ and $\mathrm{CO}_{2}$ was measured subsequently over a supported IL membrane with [APMIm]NTf ${ }_{2}$ as the IL (Fig. 3). The evolution of the permeances was followed in time at constant temperature and pressure. Feed flow rates of $100-1000 \mathrm{ml} / \mathrm{min}$ were used. The permeance of both gases remained constant for at least $10 \mathrm{~h}$. The $\mathrm{CO}_{2} / \mathrm{CH}_{4}$ permselectivity of this membrane is only slightly higher than the Knudsen selectivity of 0.6 . During the first $3 \mathrm{~h}$ after permeation of $\mathrm{CO}_{2}$, the $\mathrm{CH}_{4}$ permeance increases with $\sim 50 \%$. This behaviour is attributed to a change in the IL properties as a result of the reaction of $\mathrm{CO}_{2}$ with the amine group on the cation, producing a carbamate salt involving two imidazolium fragments [4]. The presence of this species causes a reduced $\mathrm{CH}_{4}$ permeance, which increases to its final level only after decomposition of the carbamate salt during the first $3 \mathrm{~h}$ after switching to $\mathrm{CH}_{4}$. The permeance values in the range of $1 \times 10^{-8} \mathrm{~mol} / \mathrm{m}^{2} \mathrm{~Pa}$ are lower than those found for zeolite membranes, such as silicalite-1, [20] SAPO-34, [21] and similar to those found for polymer membranes at comparable effective membrane thickness [22].

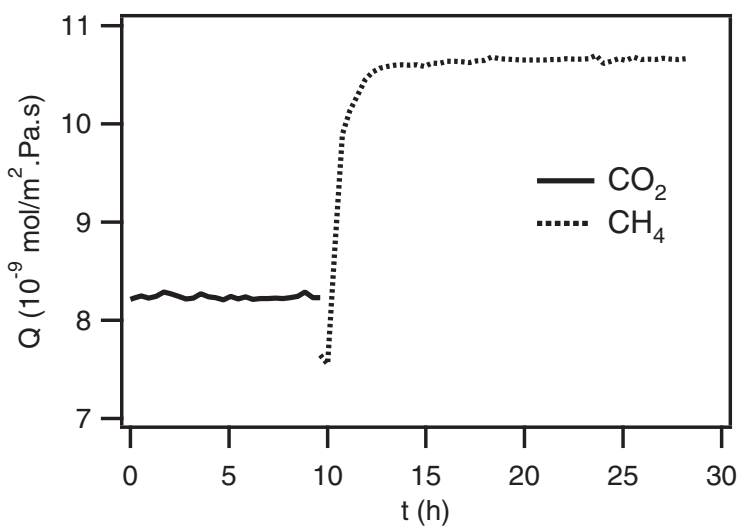

Fig. 3. Permeance versus time of $\mathrm{CO}_{2}$, measured first (solid line), and $\mathrm{CH}_{4}$, measured last (dashed line), over a [APMIm] $\mathrm{NTf}_{2}$ membrane. 
Table 1

Permeance $Q\left(10^{-9} \mathrm{~mol} / \mathrm{m}^{2} \mathrm{Pas}\right)$ of nitrogen, ethane, and ethylene for [BMIm]TFA and [BMIm]TFA.AgTFA membranes at RT; error in the last digit is shown between brackets.

\begin{tabular}{lll}
\hline & {$[$ BMIm]TFA } & [BMIm]TFA.AgTFA \\
\hline $\mathrm{N}_{2}$ & $3.7(1)$ & $4.4(1)$ \\
$\mathrm{C}_{2} \mathrm{H}_{6}$ & $4.5(1)$ & $6.7(1)$ \\
$\mathrm{C}_{2} \mathrm{H}_{4}$ & $6.2(2)$ & $6.8(2)$ \\
\hline
\end{tabular}

Nitrogen, ethylene, and ethane permeances were measured over supported [BMIm]TFA and silver-doped [BMIm]TFA.AgTFA membranes (Table 1). The aim of the addition of the silver salt AgTFA was to increase the permeance of the olefin via silver facilitated transport. Silver salts are generally used in membranes or membrane contactor systems [23] to enhance olefin transport via a coordinative interaction of the filled olefin p-orbitals with the empty d-orbitals of the transition metal. The permeances of silver-doped and undoped [BMIm]TFA are very similar, indicating that the contribution of the silver salt to the ethylene transport is not significant. Consequently, the presence of a silver salt does not enhance the selectivity. Higher measurement temperatures for the silver-doped membrane do lead to a minor permselectivity for ethylene over ethane of just under 1.5. Presumably, decomposition of the silver salt is responsible for the absence of enhanced olefin transport. Permeance values of these supported ionic liquid membranes are low; as they are in the corresponding polymer-supported IL membranes [7-10]. We assessed that at least a ten-fold increase of permeance is needed for both $\mathrm{CO}_{2} / \mathrm{CH}_{4}$ and ethylene/ethane separation to reach industrial viability.

Although these ionic liquids were selected based on suitable absorption behaviour for, their separation performance as supported liquid membrane is disappointing. Transport through liquid membrane layers is governed by thermodynamic dissolution equilibria and kinetic factors like the rates of diffusion and of uptake and release. The (static) absorption data shows an encouraging absorption capacity and selectivity. However, the membrane experiments show that the overall kinetics impart suitable membrane performance. More extended studies are required to clarify whether the diffusion, or the dissolution/desorption processes play a decisive role. The long equilibration times when switching from $\mathrm{CO}_{2}$ to $\mathrm{CH}_{4}$ suggest that the desorption kinetics severely limit permeation rates in that case. The carbamate formation may play a determining role in this process. Consequently, the applicability of ceramicsupported IL membranes mainly depends on the availability of suitable ILs. An alternative explanation for the observed behaviour is that the solubility and transport properties of the IL are influenced by the confinement in the mesopores.

In summary, a pressure resistant alumina support system was developed that is suitable for containing liquid membranes with a surface tension of at least $30 \mathrm{mN} / \mathrm{m}$, such as ILs. The ionic liquid layer is contained in the mesoporous support layer and has a thickness of around $1.5 \mu \mathrm{m}$. The liquid membrane remains intact under pressure drops up to 55 bar. The stability of the liquid membrane layer was demonstrated by the constant gas permeance over time. To enhance the limited permeance and (perm)selectivity of these membranes, we focus on (ionic) liquids in which gases dissolve physically without chemical reactions and that shows improved kinetics for especially the diffusion and desorption steps.

\section{Acknowledgements}

This research was carried out in cooperation with the University of Twente, Hyflux CEPAration, TNO, and Shell. J. de With from
Shell Technology Centre Amsterdam is acknowledged for providing the functionalized ILs. This research was partly funded by the Dutch EET (Economy, Ecology, Technology) Program, grant number $01009 / 4800000255$.

\section{Appendix A. Supplementary data}

Supplementary data associated with this article can be found, in the online version, at doi:10.1016/j.memsci.2010.12.024.

\section{References}

[1] (a) J.H. Davis, P.A. Fox, From curiosities to commodities: ionic liquids begin the transition, Chem. Commun. 11 (2003) 1209;

(b) K.R. Seddon, Room-temperature ionic liquids: neoteric solvents for clean catalysis, Kinet. Catal. 37 (1996) 693;

(c) T. Welton, Room-temperature ionic liquids. Solvents for synthesis and catalysis, Chem. Rev. 99 (1999) 2071.

[2] T. Schäfer, L.C. Branco, R. Fortunato, P. Izak, C.M. Rodrigues, C.A.M. Afonso, J.G. Crespo, Ionic Liquids IIIB: Fundamentals, Progress, Challenges and Opportunities, 2005 (Chapter 8, pp. 97-110).

[3] L.M. Galán-Sánchez, G.W. Meindersma, A.B. de Haan, Solvent properties of functionalized ionic liquids for $\mathrm{CO}_{2}$ absorption, Chem. Eng. Res. Des. 85 (2007) 31.

[4] E.D. Bates, R.D. Mayton, I. Ntai, J.H. Davis, $\mathrm{CO}_{2}$ capture by a task-specific ionic liquid, J. Am. Chem. Soc. 124 (2002) 926.

[5] G.W. Meindersma, L.M. Galán-Sánchez, A.R. Hansmeier, A.B. de Haan, Application of task-specific ionic liquids for intensified separations, Chem. Monthly 138 (2007) 1125.

[6] A. Maiti, Theoretical screening of ionic liquid solvents for carbon capture, ChemSusChem 2 (2009) 628.

[7] S. Hanioka, T. Maruyama, T. Sotani, M. Teramoto, H. Matsuyama, K. Nakashima, M. Hanaki, F. Kubota, M. Goto, $\mathrm{CO}_{2}$ separation facilitated by task-specific ionic liquids using a supported liquid membrane, J. Membr. Sci. 314 (2008) 1.

[8] R. Fortunato, C.A.M. Afonso, M.A.M. Reis, J.G. Crespo, Supported liquid membranes using ionic liquids: study of stability and transport mechanisms, J. Membr. Sci. 242 (2004) 197.

[9] M. Matsumoto, Y. Inomoto, K. Kondo, Selective separation of aromatic hydrocarbons through supported liquid membranes based on ionic liquids, J. Membr. Sci. 246 (2005) 77.

[10] C. Myers, H. Pennline, D. Luebke, J. Ilconich, J.K. Dixon, E.J. Maginn, J.F. Brennecke, High temperature separation of carbon dioxide/hydrogen mixtures using facilitated supported ionic liquid membranes, J. Membr. Sci. 322 (2008) 28.

[11] R.B. Eldridge, Olefin/paraffin separation technology: a review, Ind. Eng. Chem. Res. 32 (1993) 2208.

[12] R.W. Baker, K. Lokhandwala, Natural gas processing with membranes: an overview, Ind. Eng. Chem. Res. 47 (2008) 2109.

[13] F.F. Krull, M. Hechinger, W. Kloeckner, M. Verhuelsdonk, F. Buchbender, H. Giese, T. Melin, Ionic liquid imbibition of ceramic nanofiltration membranes, Colloids Surf. A 345 (2009) 182.

[14] S.H. Barghi, M. Adibi, D. Rashtchian, An experimental study on permeability, diffusivity, and selectivity of $\mathrm{CO}_{2}$ and $\mathrm{CH}_{4}$ through [bmim] $\left[\mathrm{PF}_{6}\right]$ ionic liquid supported on an alumina membrane: Investigation of temperature fluctuation effects, J. Membr. Sci. 362 (2010) 346-352.

[15] F.F. Krull, C. Fritzmann, T. Melin, Liquid membranes for gas/vapor separations, J. Membr. Sci. 325 (2008) 508-519.

[16] B.E. Yoldas, Alumina gels that form porous transparent alumina, J. Mater. Sci. 10 (1975) 1856

[17] B.C. Bonekamp, in: A.J. Burggraaf, L. Cot (Eds.), Fundamentals of Inorganic Membrane Science and Technology, vol. 4, Elsevier, Amsterdam, 1996, pp. 141-221 (Chapter 6).

[18] B.C. Bonekamp, A. van Horssen, L.A. Correia, J.F. Vente, W.G. Haije, Macroporous support coatings for molecular separation membranes having a minimum defect density, J. Membr. Sci. 278 (2006) 349.

[19] L.M. Galán-Sánchez, Functionalized ionic liquids: absorption solvents for carbon dioxide and olefin separation, Ph.D. Thesis, Eindhoven University of Technology, 2008.

[20] W. Zhu, P. Hrabanek, L. Gora, F. Kapteijn, J.A. Moulijn, Role of adsorption in the permeation of $\mathrm{CH}_{4}$ and $\mathrm{CO}_{2}$ through silicalite- 1 membrane, Ind. Eng. Chem. Res. 45 (2006) 767.

[21] S. Li, J.G. Martinek, J.L. Falconer, R.D. Noble, High-pressure $\mathrm{CO}_{2} / \mathrm{CH}_{4}$ separation using SAPO-34 membranes, Ind. Eng. Chem. Res. 44 (2005) 3220.

[22] S. Sridhar, B. Smitha, T.M. Aminabhavi, Separation of carbon dioxide from natural gas mixtures through polymeric membranes - a review, Sep. Purif. Rev. 36 (2001) 113.

[23] D.C. Nijmeijer, T. Visser, R. Assen, M. Wessling, Super selective membranes in gas-liquid membrane contactors for olefin/paraffin separation, J. Membr. Sci. 232 (2004) 107 (and references cited therein). 
Letter to the Editor / Journal of Membrane Science 370 (2011) 175-178

Robert Kreiter

Johan P. Overbeek

Luci A. Correia

Jaap F. Vente*

Energy research Centre of the Netherlands, P.O. Box

1,1755 ZG Petten, The Netherlands
* Corresponding author. Tel.: +31 224 564949;

fax: +31 224568615

E-mail address: vente@ecn.nl (J.F. Vente)

13 July 2010

Available online 8 January 2011 